\title{
Geothermal Anomaly Mapping Using Landsat ETM+ Data in Ilan Plain, Northeastern Taiwan
}

\author{
Hai-Po Chan, ${ }^{1}$ Chung-Pai Chang, ${ }^{2}$ and Phuong D. Dao ${ }^{3}$
}

\begin{abstract}
Geothermal energy is an increasingly important component of green energy in the globe. A prerequisite for geothermal energy development is to acquire the local and regional geothermal prospects. Existing geophysical methods of estimating the geothermal potential are usually limited to the scope of prospecting because of the operation cost and site reachability in the field. Thus, explorations in a large-scale area such as the surface temperature and the thermal anomaly primarily rely on satellite thermal infrared imagery. This study aims to apply and integrate thermal infrared (TIR) remote sensing technology with existing geophysical methods for the geothermal exploration in Taiwan. Landsat 7 (L7) Enhanced Thematic Mapper Plus (ETM+) imagery is used to retrieve the land surface temperature (LST) in Ilan plain. Accuracy assessment of satellite-derived LST is conducted by comparing with the air temperature data from 11 permanent meteorological stations. The correlation coefficient of linear regression between air temperature and LST retrieval is 0.76 . The MODIS LST product is used for the cross validation of Landsat derived LSTs. Furthermore, Landsat ETM+ multi-temporal brightness temperature imagery for the verification of the LST anomaly results were performed. LST Results indicate that thermal anomaly areas appear correlating with the development of faulted structure. Selected geothermal anomaly areas are validated in detail by field investigation of hot springs and geothermal drillings. It implies that occurrences of hot springs and geothermal drillings are in good spatial agreement with anomaly areas. In addition, the significant low-resistivity zones observed in the resistivity sections are echoed with the LST profiles when compared with in the Chingshui geothermal field. Despite limited to detecting the surficial and the shallow buried geothermal resources, this work suggests that TIR remote sensing is a valuable tool by providing an effective way of mapping and quantifying surface features to facilitate the exploration and assessment of geothermal resources in Taiwan.
\end{abstract}

1 Department of Earth Sciences and Graduate Institute of Geophysics, National Central University, Jhongli 32001, Taiwan. E-mail: haipochan@g.ncu.edu.tw

2 Center for Space and Remote Sensing Research, National Central University, Jhongli 32001, Taiwan. E-mail: cpchang@csrsr.ncu.edu.tw

3 Department of Geography, University of Toronto, 3359 Mississauga Rd, Mississauga, ON L5L 1C6, Canada. E-mail: phuong.dao@mail.utoronto.ca
Key words: Ilan plain, thermal infrared (TIR) remote sensing, Landsat $7 \mathrm{ETM}+$, land surface temperature (LST), geothermal anomaly, geothermal exploration.

\section{Introduction}

Remotely sensed thermal infrared (TIR) images have been used to detect geothermal activity for over half a century. In 1961, a geothermal survey on Yellowstone National Park of USA initiated the application of TIR remote sensing in geothermal exploration, which the US Army Cold Regions Research and Engineering Laboratory incorporated with the University of Michigan successfully identified hot springs and other near-surface geothermal anomalies with thermal infrared scanning technique (Qin et al. 2011). Land surface temperature (LST) is required in the assessment of remote sensing to detect shallow thermal anomalies for geothermal exploration and field management. LST is also used as an indicator of the thermal information associated with faults or volcanic complexes (Gaudin et al. 2013; Gutiérrez et al. 2012; Wu et al. 2012) and as a key factor to obtain surface heat fluxes for a variety of investigations such as urban heat island (UHI) effect and land-air interactions (Chang et al. 2010; Chang and Liou 2005; Chien et al. 2008). Hence LST with relatively high accuracy is needed in the assessment of potential area for geothermal resource. This information can be retrieved from Landsat 7 ETM+ data provided by US Geological Survey (USGS) archives. A body of literature has shown that it is feasible to conduct the assessment of LST or geothermal heat flux (GHF) from high spatial resolution satellite data (Akhoondzadeh 2013; Davies et al. 2008; Gutiérrez et al. 2012; Kruse 2012; Kuenzer et al. 2007; Mia et al. 2012, 2013; Oguro et al. 2011; Qin et al. 2011; Reath and Ramsey 2013; 
Shaw et al. 2010; Vaughan et al. 2010, 2012; Wu et al. 2012). However, it appears that there is no previous study of geothermal exploration using satellite-based infrared data in Taiwan. This work aims to apply TIR remote sensing for the geothermal exploration in Ilan plain of Taiwan.

\subsection{Geothermal Energy of Taiwan}

Considering the geodynamic setting, geothermal energy holds promising for the Taiwan Island. Taiwan is located in the Pacific Rim of Fire and possesses rich geothermal resources because of volcanic activities originating from the plate convergence. Previous reports from Taiwan's Bureau of Energy suggest that Taiwan has geothermal power potential in excess of $33.6 \mathrm{GWe}$ (Tsanyao 2015), which would be sufficient for the island's annual electricity demand when fully tapped. In addition, the ongoing debate on the safety of nuclear power, which currently accounts for around 20\% of Taiwan's power, has shifted focus on alternative renewable energies, especially after the 2011 Fukushima nuclear power plant accident in Japan. In this regard, geothermal energy appears as one of the best alternatives to replace nuclear and provide clean electricity for the island.

Ilan plain (around $330 \mathrm{~km}^{2}$; Fig. 1) in the northeastern Taiwan is a geologically active area affiliated with the Okinawa Trough. It is a deltaic plain with the flat topography which is surrounded by the Hsuehshan Range to the northwest and the Backbone Range to the Southeast. The study area is mainly covered by Oligocene to Miocene rocks (shale and sandstone in the main) and quaternary alluvial deposits, which is acquired from Ho's 1:50,000 Geology Map of Taiwan as shown in Fig. 2 (Ho and Chen 2000). The shallow geothermal potential in Ilan plain was evaluated by thermal gradients (TGs) of 30 water wells (27-178 $\mathrm{m}$ in depth) from 2003 to 2005, and the probable heat source of the high geothermal is the volcanic intrusion beneath the plain (Chiang et al. 2007; Tong et al. 2008). The National Science and Technology Program-Energy (NSTPE) was established in December 2007 by the National Science Council (NSC; now renamed as Ministry of Science and Technology, MOST) for integrating resources and formulating an energy technology development strategy. This MOST's master project of geothermal energy intends to drill a well of $3000 \mathrm{~m}$ to build up a $1 \mathrm{MW}$ geothermal pilot power plant, by dint of developing the exploration and evaluation techniques of the deep enhanced geothermal system (EGS) (Song 2016; Tsanyao 2015).

Obviously, geothermal energy development in Taiwan presents opportunities both for the renewable energy and economic growth in the island. Various studies in Ilan plain have been conducted by existing geophysical methods, such as seismic tomography, gravity gradiometry, electrical resistivity tomography, magnetic prospecting, and well logging. However, Satellite remote sensing data such as Landsat is not yet integrated into this arena in Taiwan. Thus, this research proposes a top-down approach for detecting geothermal anomaly in Taiwan based on the largest free source of Landsat data provided by the USGS.

\subsection{Geomagnetic, Gravity, and Magnetotelluric Survey in the Ilan Plain and Chingshui Area}

The Chingshui geothermal field in the southwest of Ilan plain is the most productive geothermal area in Taiwan. Various geophysical methods have been performed for the exploration in the region. For instance, a geomagnetic survey in the Ilan plain was conducted in 1978. The acquired dataset of 425 stations has been reprocessed in 2008 for analyzing the possible heat sources and fluid channels of the geothermal field. As a result, the surface projection of the fault and dyke solutions in the Ilan plain is shown in Fig. 3. Three groups of dyke solutions were identified in the northern part of Ilan plain as shown in Fig. 3a, and three groups of fault solutions were observed as shown in Fig. 3b. In addition, a gravity survey in the Chingshui area was performed by the ITRI (Industrial Technology Research Institute of Taiwan) in 1976, and data of 636 stations were collected. This dataset has been reprocessed to analyze fault structures in the Chingshui area. Besides, the magnetotelluric (MT) survey method has been utilized to explore the structure of the geothermal reservoir in the Chingshui area in 2006, in 


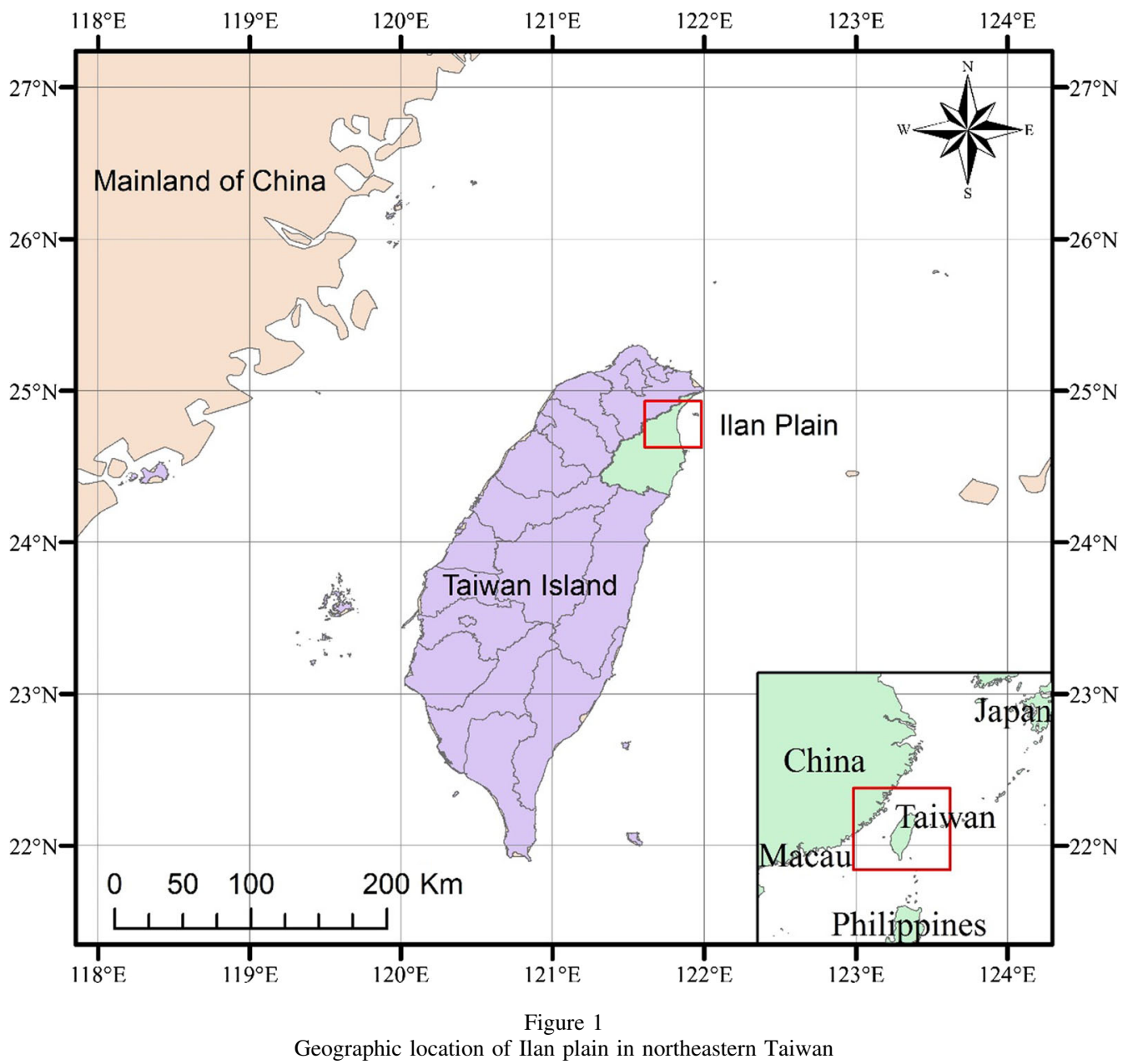

which 33 broadband magnetotelluric data points were acquired by the ITRI (Tong et al. 2008).

Clearly, the integration of the above-mentioned geophysical methods strives to delineate the insight of the geothermal structure in the Ilan plain. They have drawn the preliminary conclusion: (1) the presence of a magma chamber in the shallow crust and shallow intrusive igneous rock causes the high heat flow and geothermal gradient in the Ilan plain. (2) Geothermal fluid circulated within the fracture zone in the deep was heated by the hot rock in the Chingshui geothermal field, and the geothermal reservoir of the Chingshui geothermal field likely linked with the fracture zone of the Chingshuihsi fault (Tong et al. 2008).

\section{Data and Method}

This research uses Landsat 7 ETM+ LT1 data products. The Landsat scene covers northern part of Taiwan (WRS2 Path/Row 117/43; acquisition time: UTC 02:09:19) obtained on December 3, 2001 (Fig. 4). Each scene size by default is about $170 \mathrm{~km}$ north-south by $183 \mathrm{~km}$ east-west (106 mile by 114 mile). The image is in good quality of rank 9 (image quality ranges from 0 to 9 with 9 being the best). Clear weather condition was presented with average wind speed of $2.3 \mathrm{~m} / \mathrm{s}$ and no precipitation according to the meteorological report of Central Weather Bureau (CWB). Landsat scenes are processed to Standard Terrain Correction (Level 1T-precision and terrain correction) which gives systematic radiometric and geometric accuracy through 

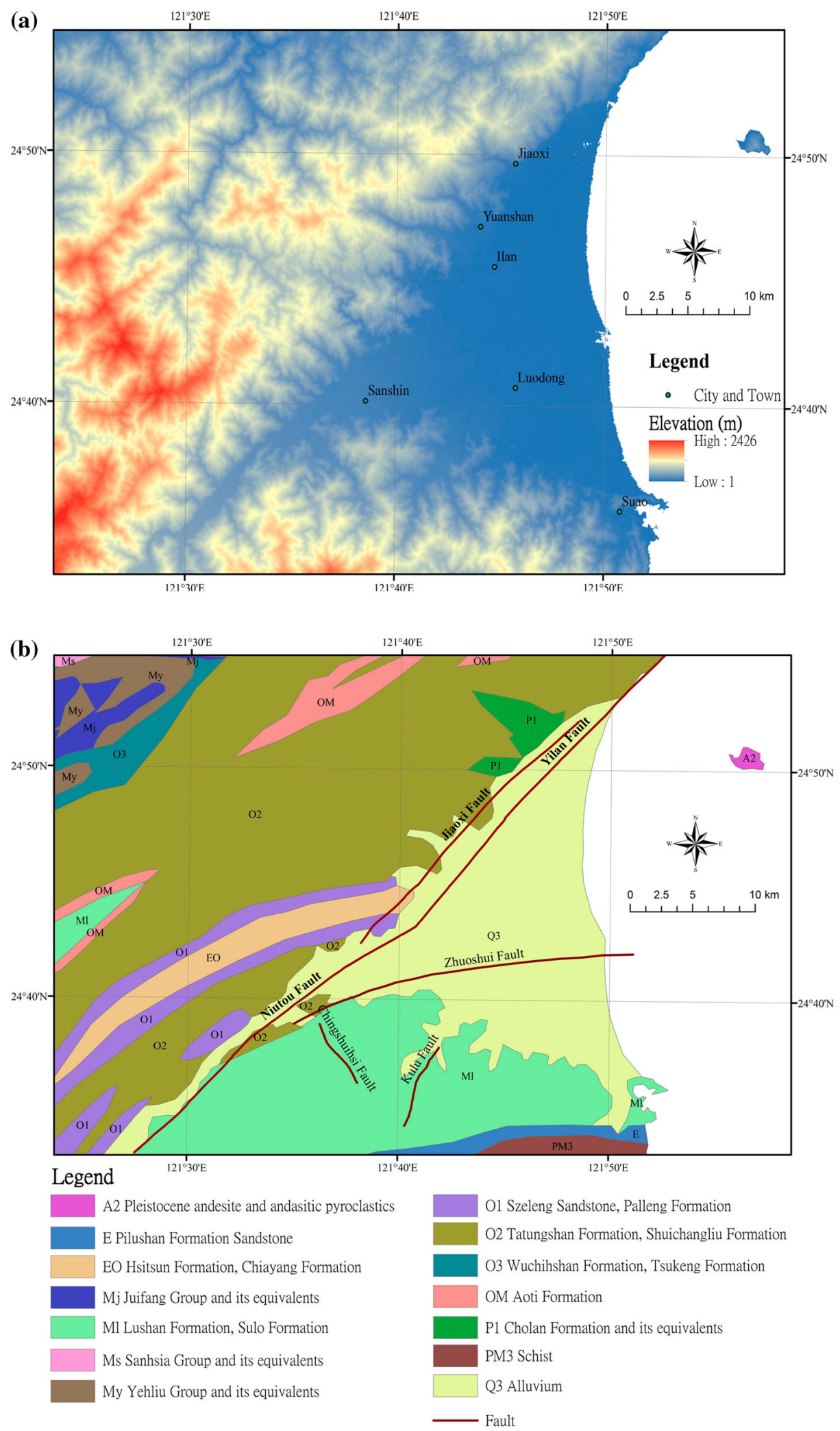
Figure 2

a The topographic and $\mathbf{b}$ geologic map of the study area. Major faults (Kang et al. 2015; Lee 1999; Liu 1995; Tong et al. 2008) were illustrated on the geologic map

integrating ground control points and topographic accuracy by the digital elevation model (DEM) (NASA 2015).

\subsection{Landsat 7 Products}

The Landsat program is a civilian satellite program that was initiated in 1965 by the USGS. First satellite Landsat 1 was launched on July 23, 1972. Landsat 7 (launched in 1999) and Landsat 8 (launched in 2013) are currently active missions. Landsat 7 Enhanced Thematic Mapper Plus (ETM+) imagery contains eight spectral bands. The spatial resolution for Bands $1-5$ and 7 is $30 \mathrm{~ms}$, Band 6 is $60 \mathrm{~m}$, and for Band 8 (panchromatic) is $15 \mathrm{~m}$. All bands can acquire one of two gain settings (high or low) depending on radiometric sensitivity and dynamic range, while Band 6 (thermal band) collects both high and low gain for all scenes (NASA 2013). Table 1 provides selected features of the Band 6 (thermal band) of the instrument.

\subsection{Data Processing}

The physical basis of LST retrieval is the Blackbody Radiation and the Planck Function. Planck Function is employed for calculating the radiance emitted from a "Black Body". Inverse of the Planck Function is to derive the "brightness temperature" of an object. Landsat 7 ETM+ sensor acquires radiance information and stores it to the format of digital number (DN) in the range between 0 and 255 . So the LST can be retrieved by converting these DN values to degrees Kelvin or Celsius. In this study, main steps of data processing include radiometric calibration, atmospheric correction, topographic correction and emissivity calculation. Specific procedures are illustrated as shown in Fig. 5.

Radiometric calibration is applied as the first step to convert the $\mathrm{DN}$ value into the top of atmosphere (TOA) radiance according to formulas from the Landsat 7 Science Data Users Handbook
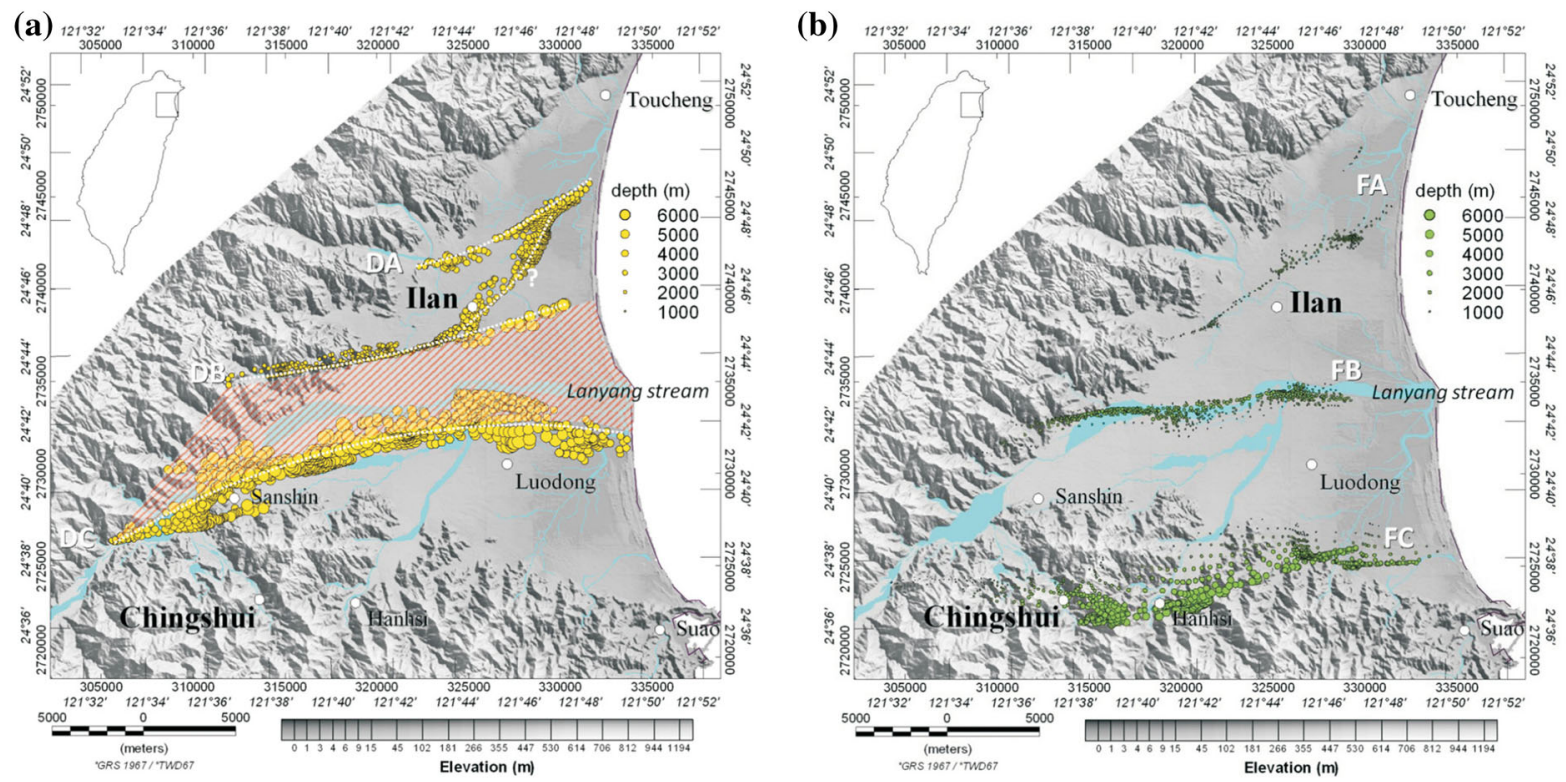

Figure 3

The surface projection of the fault and dyke solutions in the Ilan plain. a Three groups of dykes (DA, DB and DC) were noticed. b Three groups of faults (FA, FB and FC) were observed. The solid yellow and green circles indicate the depth of fault and dyke solutions beneath the Ilan plain, respectively. The shaded area between DB and DC could be related to the WE high magnetic anomaly area associated with igneous intrusive rock (Tong et al. 2008) 


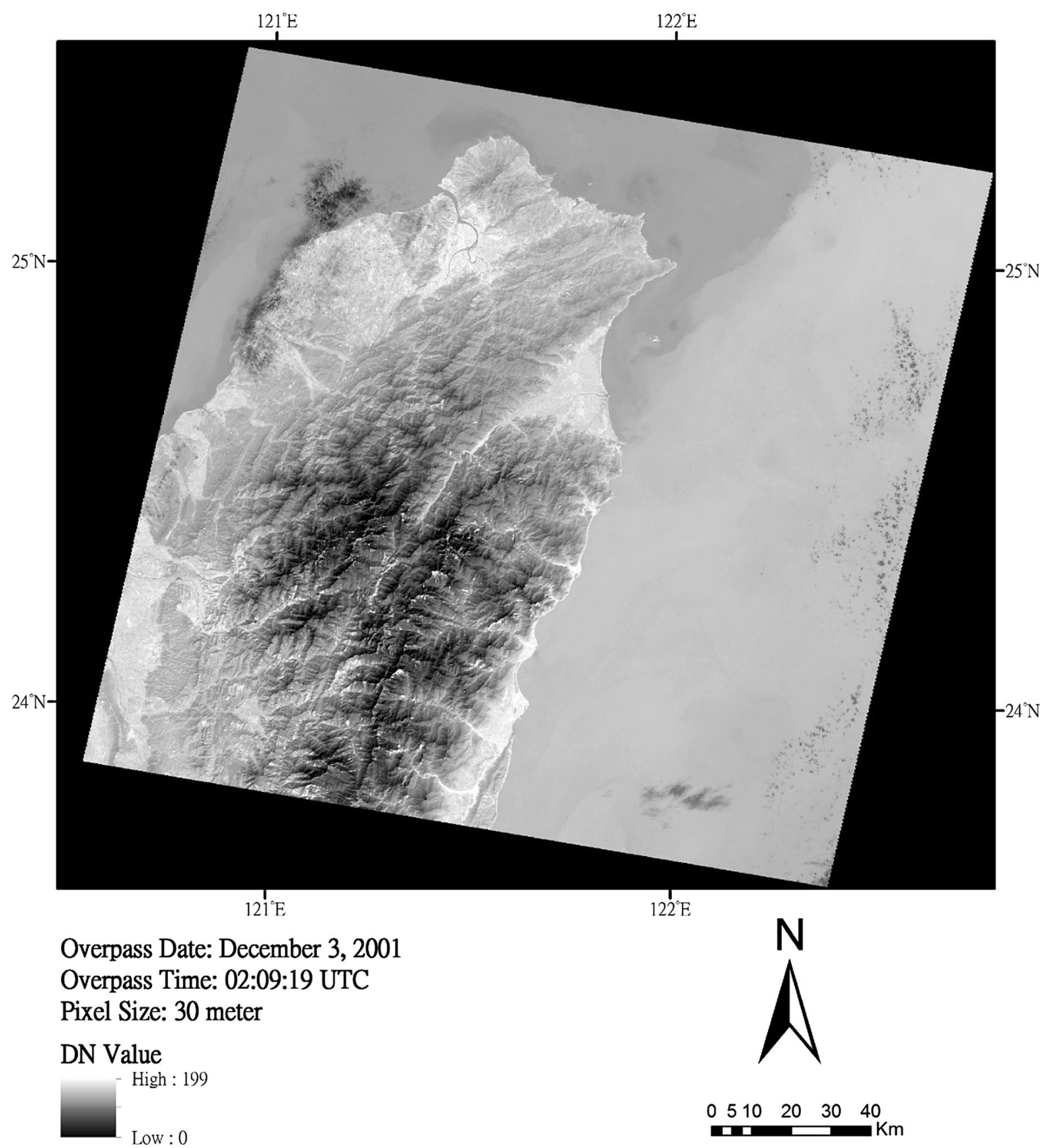

Figure 4

Landsat 7 ETM+ thermal infrared image acquired on December 3, 2001

(NASA 1998). Two Atmospheric Correction Modules are adopted to Landsat scene depending on the wavelengths. For wavelengths in the visible through near-infrared and shortwave infrared regions (up to
$3 \mu \mathrm{m}$ ), fast line-of-sight atmospheric analysis of spectral hypercubes (FLAASH) is applied. FLAASH is a first-principles atmospheric correction tool incorporating the MODTRAN (MODerate resolution 
Table 1

Selected features of the thermal bands of Landsat 7 ETM+

\begin{tabular}{lllll}
\hline Sensor & FWHM $(\mu \mathrm{m})^{\mathrm{a}}$ & Spatial resolution $(\mathrm{m})$ & NE $\Delta \mathrm{T}(\text { at } 280 \mathrm{~K})^{\mathrm{b}}$ & Temperature range $(\mathrm{K})$ \\
\hline Landsat 7 ETM+ & $10.31-12.36$ & $60(30)$ & H: 0.22 & H: $240-320$ \\
& & & L: 0.28 & L: $130-350$ \\
\hline
\end{tabular}

The applicable temperature range is confined by the detectors' sensitivity at the minimum $\mathrm{Ne} \Delta \mathrm{T}$ and the rescaling factors for the geometrically corrected product. All bands of Landsat 7 ETM+ have high $(\mathrm{H})$ and low (L) Gain settings (Butler et al. 2005). Note that the resolution of Band 6 (thermal band) is collected at 60-m. Products are resampled to 30-m pixels after February 25, 2010

${ }^{a}$ Full width half maximum (FWHM) is used to describe the width of a spectral emission at the $50 \%$ amplitude points

${ }^{b}$ Noise-equivalent change in temperature (NE $\Delta \mathrm{T}$ ) is used to quantify image noise level (i.e., the sensitivity of the sensor) for thermal infrared data. NE $\Delta \mathrm{T}$ is defined as the amount of incident signal temperature needed to match the internal noise of the sensor of thermal radiation such that the signal-to-noise ratio is equal to one

atmospheric TRANsmission) radiation transfer model to compensate for atmospheric effects, which is being established by the Air Force Phillips Laboratory, Hanscom AFB and Spectral Sciences, Inc. (AdlerGolden et al. 1998). For the thermal band, National Aeronautics and Space Administration (NASA) provide a web-based atmospheric correction tool "The Atmospheric Correction Parameter Calculator" for single thermal band sensors on the website (http:// atmcorr.gsfc.nasa.gov/). It adopts atmospheric global profiles (modeled by the National Centers for Environmental Prediction; NCEP) for a specific date, time and location as input. It also uses MODTRAN model; the site-specific atmospheric transmission, and upwelling and downwelling radiances can be calculated from the calculator (Barsi et al. 2003).

In areas with rugged terrain, topographic correction can be carried out to remove the topographic effects. Both the optical and thermal bands are influenced by topographical variations in solar illumination. A number of methods for normalizing these effects in images have been developed. Amongst them the most used are empirical approaches which are based on regression and model-based methods which assume Lambertian reflectance (Warner and Chen 2001). In this research, Lambertian cosine correction (C-Correction) based on the 20-m-resolution DEM from the Department of Land Administration, Ministry of the Interior, Taiwan is applied for Topographic Correction. The Lambertian model defines that reflected radiance from the inclined surface $\left(L_{\mathrm{T}}\right)$ is related to the horizontal surface $\left(L_{\mathrm{H}}\right)$ by the following equation:

$$
L_{\mathrm{T}}=L_{\mathrm{H}} \cdot \cos i / \cos z,
$$

where $i$ is the incidence angle (the angle between the illumination and the normal to the surface) and $z$ is the sun zenith angle (the angle between the vertical and the sun).

Emissivity calculation uses the general method to incorporate emissivity as a function of the atmospherically corrected red and near-infrared bands. It is based on the work of Sobrino et al. (2001) and referred to as NDVI (Normal Differential Vegetation Index) threshold methods. For further elaboration, emissivity of each pixel in the imagery is derived from vegetation fraction $\left(F_{\mathrm{r}}\right)$ from NDVI. NDVI is defined as a function of the surface derived reflectance in the red band $\left(R_{\text {red }}\right)$ and the nearinfrared band $\left(R_{\text {nir }}\right)$ : i.e.,

$$
\mathrm{NDVI}=\frac{R_{\mathrm{nir}}-R_{\mathrm{red}}}{R_{\mathrm{nir}}+R_{\mathrm{red}}}
$$

Vegetation fraction $\left(F_{\mathrm{r}}\right)$ is defined as the ratio of the vertical projection over the vegetation canopy in each pixel: i.e.,

$$
F_{\mathrm{r}}=\left(\frac{\mathrm{NDVI}-\mathrm{NDVI}_{\mathrm{s}}}{\mathrm{NDVI}_{\mathrm{v}}-\mathrm{NDVI}_{\mathrm{s}}}\right)^{2},
$$

where $\mathrm{NDVI}_{\mathrm{s}}$ is the NDVI value corresponding to bare soil, and $\mathrm{NDVI}_{\mathrm{v}}$ is the value corresponding to full vegetation. $\mathrm{NDVI}_{\mathrm{v}}$ as 0.87 and NDVIs as 0.22 are proximately taken according to the NDVI histogram values of the study area. Considering the various landcover of the study area, emissivity values can be calculated in three cases: 


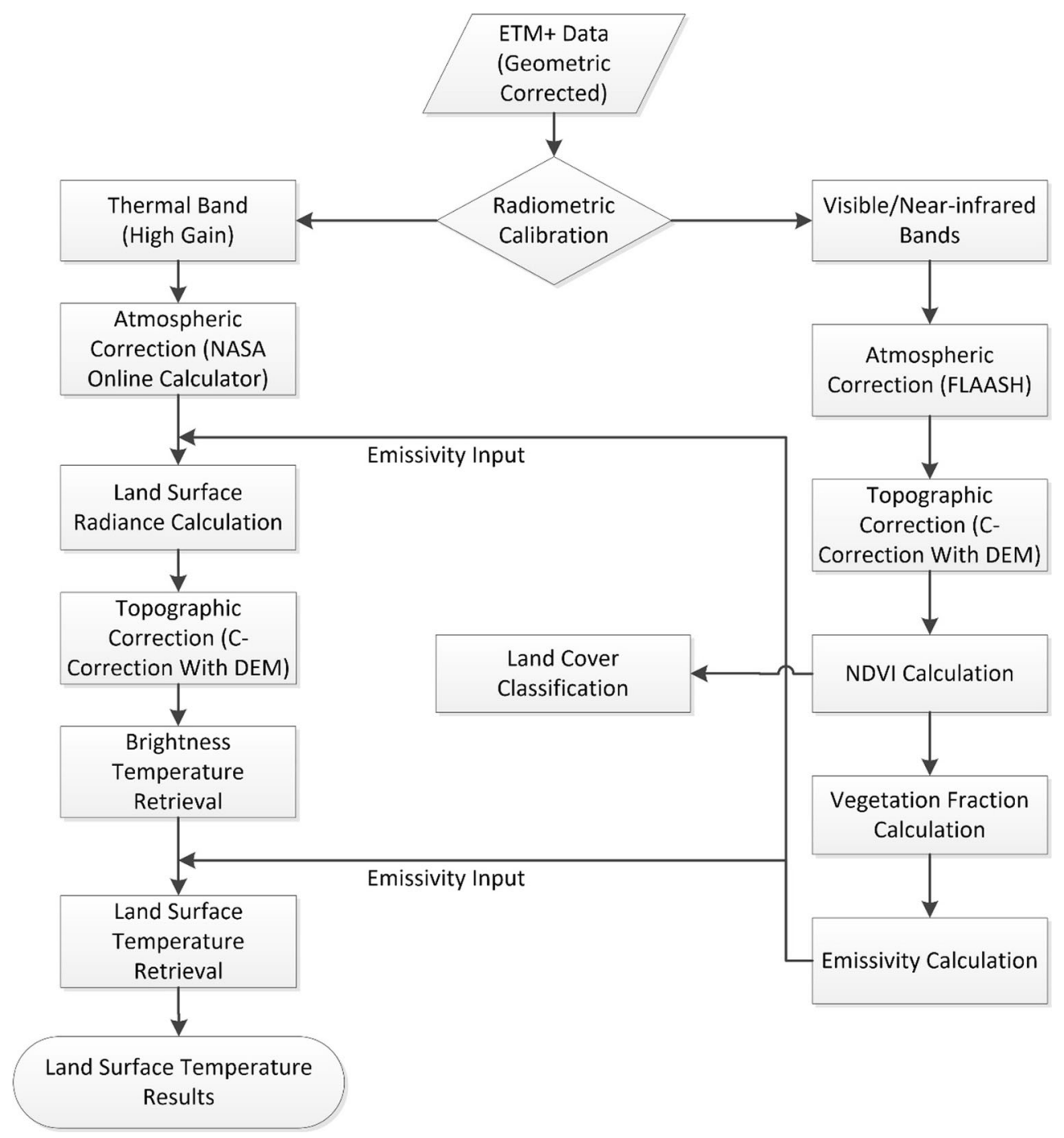

Figure 5

Flow chart of LST retrieval

(a) NDVI $<0.22$, the pixel is mainly bare soil $\left(F_{\mathrm{r}}=0\right)$ and the mean value of soil emissivity $\left(\varepsilon_{\mathrm{s}}\right)$ is assumed as 0.97 (Sobrino et al. 2008).

(b) NDVI $>0.87$, the pixel is considered fully vegetated $\left(F_{\mathrm{r}}=1\right)$ with the mean value of vegetation emissivity $\left(\varepsilon_{\mathrm{v}}\right)$ of 0.99 (Sobrino et al. 2008).

(c) $0.22 \leq \mathrm{NDVI} \leq 0.87$, pixels are consisted of bare soil and vegetation, and the pixel level emissivity is derived from the equation as follows:

$$
\varepsilon_{\mathrm{i}}=F_{\mathrm{r}} \cdot \varepsilon_{\mathrm{v}}+\left(1-F_{\mathrm{r}}\right) \cdot \varepsilon_{\mathrm{s}},
$$

where $\varepsilon_{\mathrm{v}}$ is the vegetation emissivity, $\varepsilon_{\mathrm{s}}$ is the soil emissivity, and $\varepsilon_{\mathrm{i}}$ is the pixel's effective emissivity.

Finally, the LST result is computed from a singlechannel algorithm proposed by Artis and Carnahan (1982).

\subsection{Validation of Landsat ETM+ Derived LSTs}

Parameters retrieved from remotely sensed data can be used with confidence only after the proper accuracy assessment. Two approaches were adopted 


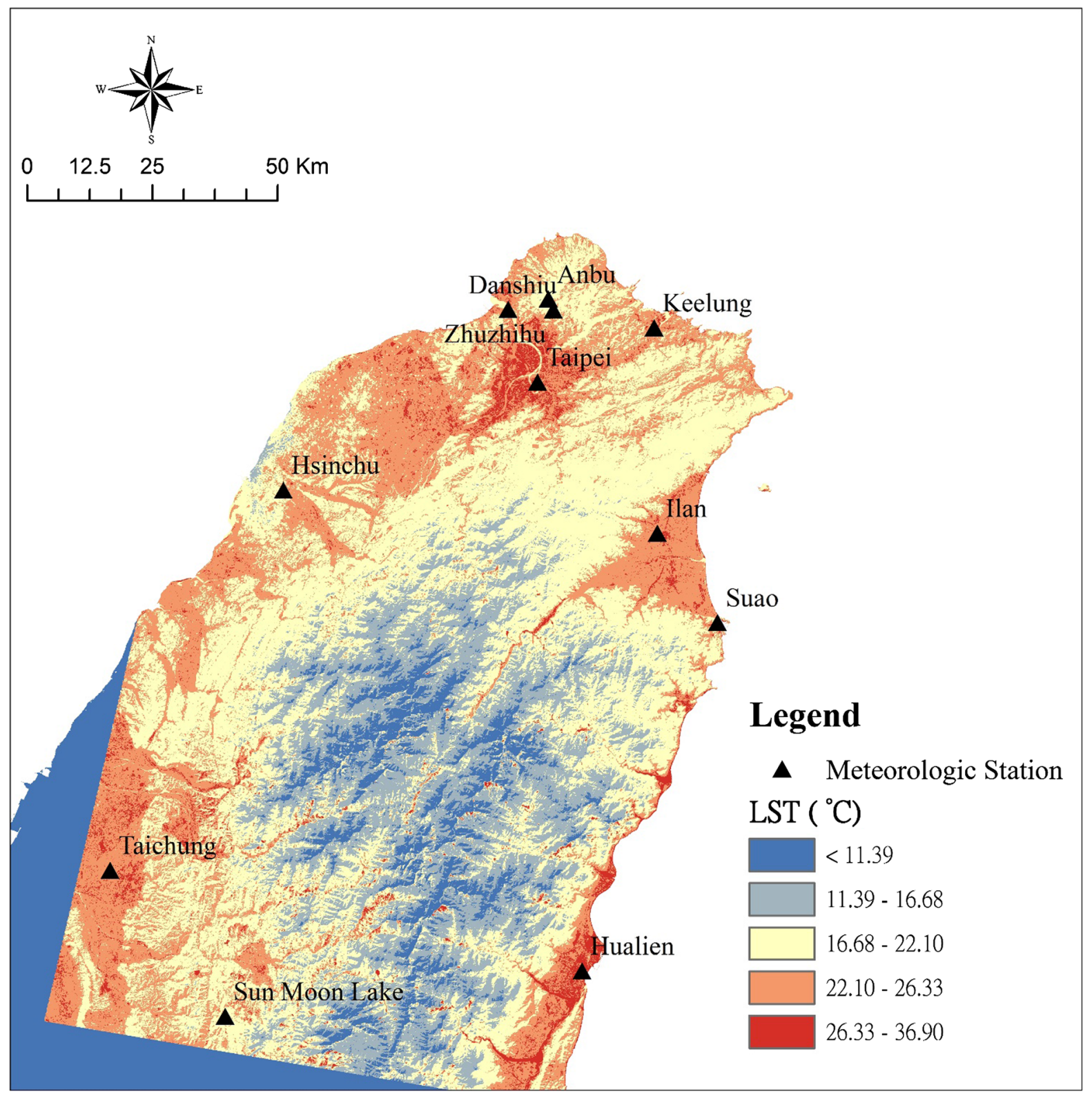

Figure 6

Geographical location of meteorological stations and the corresponding LST retrieval (scene-specific)

to assess the accuracy of the Landsat ETM+ derived LST in this study.

\subsubsection{Ground-Truth Validation from Meteorological Temperature Data}

The interpolated meteorological temperature data from Central Weather Bureau (CWB) of Taiwan at
02:09:00 UTC, 10:09:00 local time are employed to evaluate the reasonability of LST at 02:09:19 UTC, 10:09:19 local time. The 11 stations in the whole scene of imagery are selected to assess the accuracy by comparing with the LST as shown in Fig. 6 and Table 2. Figure 6 explains how the author obtains the specific points of meteorological stations for validation. The result in Table 2 shows that differences 
Table 2

LST validation by the meteorological temperature data (scene-specific)

\begin{tabular}{|c|c|c|c|c|c|c|}
\hline $\begin{array}{l}\text { Central Weather Bureau } \\
\text { (CWB) station }\end{array}$ & $\begin{array}{l}\text { Latitude } \\
\left({ }^{\circ}\right)\end{array}$ & $\begin{array}{l}\text { Longitude } \\
\left({ }^{\circ}\right)\end{array}$ & $\begin{array}{l}\text { Elevation } \\
(\mathrm{m})\end{array}$ & $\begin{array}{l}T_{\mathrm{a}} \text {, interpolated air temperature } \\
\left({ }^{\circ} \mathrm{C}\right) \text { at } 10: 09 \mathrm{AM}\end{array}$ & $\begin{array}{l}T_{\mathrm{s}} \text {, retrieved } \mathrm{LST}\left({ }^{\circ} \mathrm{C}\right) \\
\text { at 10:09 AM }\end{array}$ & $\begin{array}{l}\text { Difference }\left({ }^{\circ} \mathrm{C}\right) \\
\left(T_{\mathrm{s}}-T_{\mathrm{a}}\right)\end{array}$ \\
\hline Danshiu & 25.16 & 121.44 & 19.0 & 23.82 & 22.36 & -1.46 \\
\hline Anbu & 25.18 & 121.52 & 825.8 & 22.49 & 23.52 & 1.03 \\
\hline Taipei & 25.03 & 121.50 & 5.3 & 26.01 & 30.76 & 4.75 \\
\hline Zhuzihu & 25.16 & 121.53 & 607.1 & 22.03 & 24.66 & 2.63 \\
\hline Keelung & 25.13 & 121.73 & 26.7 & 26.87 & 26.91 & 0.04 \\
\hline Hualien & 23.97 & 121.60 & 16.0 & 26.63 & 31.30 & 4.67 \\
\hline Suao & 24.60 & 121.86 & 24.9 & 25.19 & 24.66 & -0.53 \\
\hline Ilan & 24.76 & 121.74 & 7.2 & 25.75 & 28.02 & 2.27 \\
\hline Taichung & 24.14 & 120.67 & 84.04 & 25.21 & 28.02 & 2.81 \\
\hline Hsinchu & 24.83 & 121.00 & 26.9 & 24.29 & 25.23 & 0.94 \\
\hline Sun Moon Lake & 23.88 & 120.90 & 1017.5 & 22.77 & 24.09 & 1.32 \\
\hline
\end{tabular}

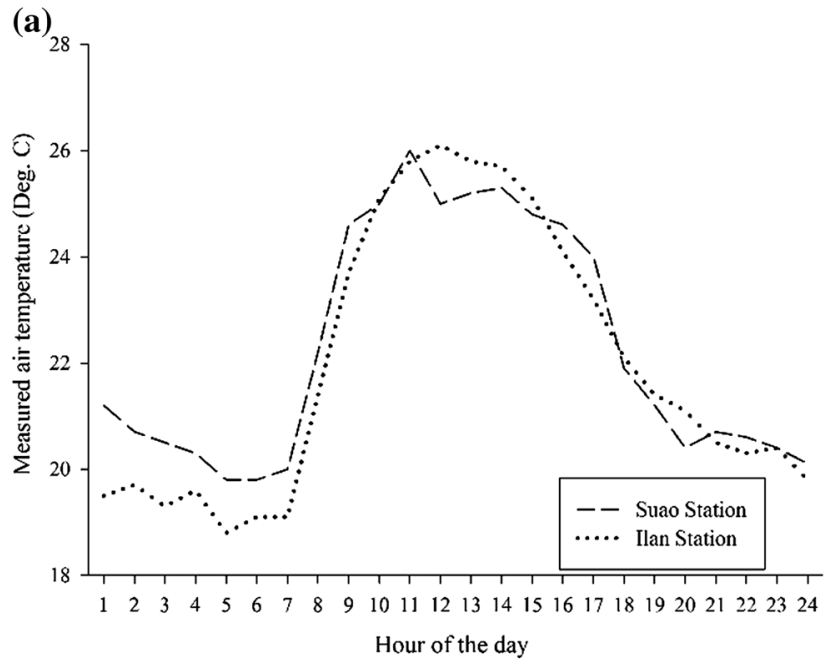

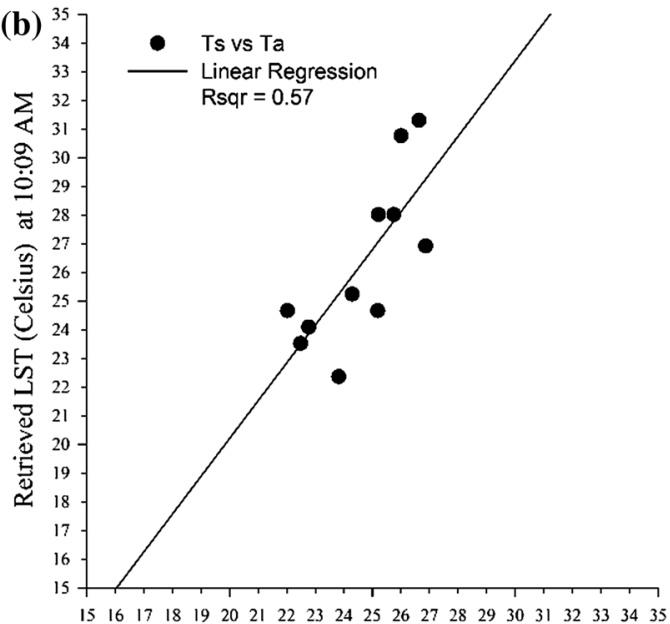

Measured (interpolated) air temperature (Celsius) at 10:09 AM

Figure 7

a CWB hourly measured air temperature variation for 2 sites in Ilan plain on December 3, 2001. b Scatter plot of the measured air temperature and retrieved LST with fitted linear curves

Table 3

Linear regression summary and parameter estimates of the measured air temperature and retrieved LST

\begin{tabular}{llll}
\hline Linear regression & $r$ & Rsqr $\left(R^{2}\right)$ & Standard error of estimate \\
\hline$T_{\mathrm{s}}$ vs. $T_{\mathrm{a}}$ & 0.76 & 0.57 & 2.01 \\
\hline
\end{tabular}

Linear regression model: $f=y_{0}+a x$

between LST and the meteorological air temperatures are in $0.53-2.27{ }^{\circ} \mathrm{C}$ in the Ilan plain (Suao station and Ilan station).

The differences can be caused by various factors. LST is influenced by wind blowing over the surface and cooling the upper few microns, and soil moisture. The temperatures may rise rapidly as the time approaches toward the noon and the highest temperatures are present at the noon 12:00:00 local time (Fig. 7a). The measured air temperature usually 


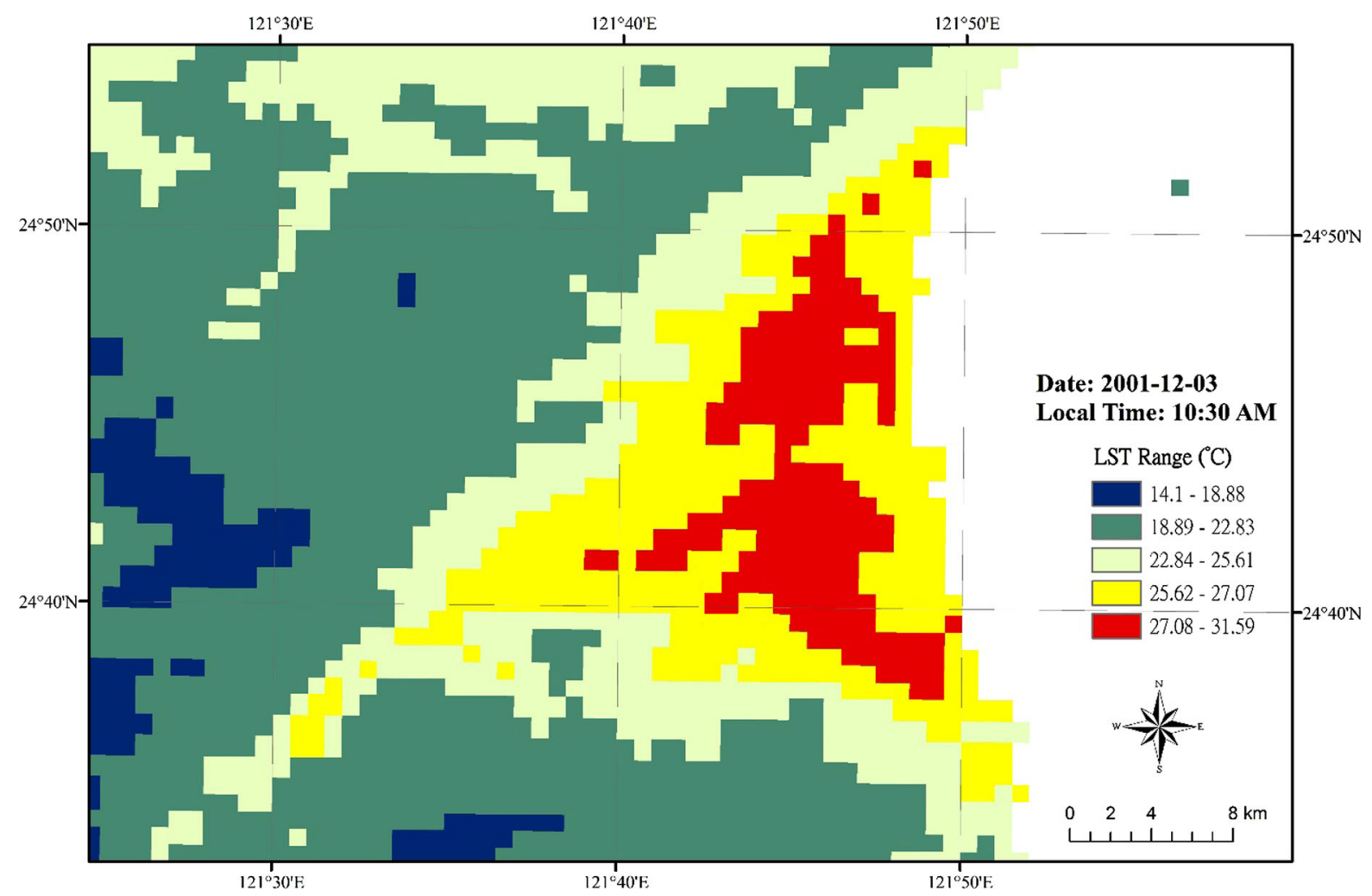

Figure 8

Pattern of LST distribution in Ilan plain from MODIS LST product on December 3, 2001. The spatial resolution of MODIS LST products is $1 \mathrm{~km}$

Table 4

Comparison on the statistics of retrieved Landsat LST and MODIS LST product in Ilan plain

\begin{tabular}{lrrr}
\hline Sensors & \multicolumn{2}{l}{ LST $\left({ }^{\circ} \mathrm{C}\right)$} & \\
\cline { 2 - 5 } & Min & Max & Mean \\
\hline Landsat ETM+ (30 m spatial resolution; overpass time 10:09 AM) & 10.80 & 36.60 & 22.92 \\
MODIS (1 km spatial resolution; overpass time 10:30 AM) & 14.09 & 31.59 & 5.01 \\
Difference & 3.29 & 0.41 \\
\hline
\end{tabular}

depends on air conditions near ground. For slight vegetated areas the day LST is higher than air temperature. At night, LST is lower than air temperature. However, this relation varies with cover types, seasons and regions. Theoretically, the thermal responding of the land surface to the time-varying energy input is determined by the thermal inertia. Thermal inertia is the key property dominating the variations of diurnal surface temperature. It depends on the physical parameters of the top few centimeters of the land surface and represents the complicated combination of rock and soil properties (Mellon et al. 2000; Price 1977).

The comparison between air temperature and LST retrieval is shown by the clustering points in Fig. 7b; the relationship is rather significant in the context of linear regression despite the limited stations (correlation coefficient 0.76). Major discrepancies can be caused by radical differences in the scales of resolution between the satellite and ground-based 
CWB meteorological stations (i.e., the scale mismatch). The stronger LST heterogeneity generally leads to the greater scale-mismatch effect. Therefore, the ground measurements may not be representative of the complex landform observed by the satellite sensor. This is especially obvious for the CWB stations viewed on non-vegetated area enclosing each tower while the major satellite footprint includes vegetated land (Quattrochi and Luvall 2004). However, in this study, despite the pros and cons of ground measurements, the only ground-truth data set available for validation is the air temperature of meteorological stations.

Furthermore, regression analysis between the measured air temperature and retrieved LST are conducted for accuracy assessment as shown in Table 3. Examinations of the results are represented by $r$, R-Squared $\left(R^{2}\right)$, and standard error.

In summary, the error of LST retrieval can be attributed as the following sources: first, converting radiances to LST contains a number of assumptions and approximations such as sensor properties. Past studies indicate the calibration error of ETM+ data acquired after December 2000 is within $\pm 0.6 \mathrm{~K}$. Second, the error stems from the accuracy of water vapor measurements using the atmospheric correction model. Taking MODTRAN atmospheric correction model for example, target temperature of $300 \mathrm{~K}$ could cause a LST error of about $0.5 \mathrm{~K}$ for ETM+ data (Schmugge et al. 1998). Third, the error may arise from the estimate of surface emissivity. The emissivity error can come from the NDVI (Normalized Difference Vegetation Index) estimation error; however, the emissivity error should be smaller than 0.005 , which leads to a variance of $0.2 \mathrm{~K}$ (ETM+ data) in the LST providing the target temperature is $300 \mathrm{~K}$ ( $\mathrm{Li}$ et al. 2004). Finally, the scale-mismatch effect is also considerably responsible for discrepancies between the point measurements and remote sensing methods.

\subsubsection{Cross Validation from MODIS LST Products}

Landsat 7 ETM+ dataset has the advantage of high spatial resolution $(60 \mathrm{~m})$ but the low temporal resolution (revisit in 16 days) is a disadvantage. Compared to Landsat 7, Terra MODIS (Moderate
Figure 9

a Pattern of LST distribution in Ilan plain from Landsat 7 ETM+ on December 3, 2001. Major thermal anomalous areas are indicated by A, B, C, D, E and F. b LULC classification map of the study area

Resolution Imaging Spectroradiometer) provides daily imagery with spatial resolution of $1 \mathrm{~km}$ in the study area. According to the general accuracy statement from MODIS land team, The LST accuracy is better than $1 \mathrm{~K}(0.5 \mathrm{~K}$ in most cases), as expected pre-launch (Coll et al. 2009). Thus, MODIS LST product is applied for the cross validation of Landsat retrieved LST. MODIS/Terra Land Surface Temperature Daily L3 Global 1 km (Product ID: MOD11A1) daytime LSTs acquired by Terra MODIS at local time 10:30 AM on December 3, 2001 is displayed in Fig. 8. The comparison on the statistics of retrieved Landsat LST and MODIS LST product in Ilan plain is shown in Table 4.

\section{Results and Discussion}

\subsection{Retrieved LSTs in Ilan Plain}

Figure 9a shows the retrieved LST distribution of Ilan plain from Landsat 7 ETM+ band 6 (High Gain setting) data on December 3, 2001. Figure 9b displays the corresponding Land Use and Land Cover (LULC) classification map based on the NDVI value. The pattern indicates that the lowest temperature in the study area is about $9{ }^{\circ} \mathrm{C}$ and the highest is $27{ }^{\circ} \mathrm{C}$ with color spanned from blue to red. Six areas with distinct red color are selected and marked with A, B, C, D, E and F. Temperatures of A, B, C, D, E and F areas are overall $3-6{ }^{\circ} \mathrm{C}$ higher compared to the ambient background temperature. The pattern of thermal anomaly is consistent with those presented in the previous studies (Chiang et al. 1979, 2007), which focus on point measurements rather than remote sensing methods.

Faults and earthquakes are closely related in the way that earthquakes occur when rocks slip along faults. Though many faults were identified in the surrounding mountain areas of Ilan plain, the features beneath the plain are not much investigated due to the thick sediment deposit. The seismicity of the Ilan 

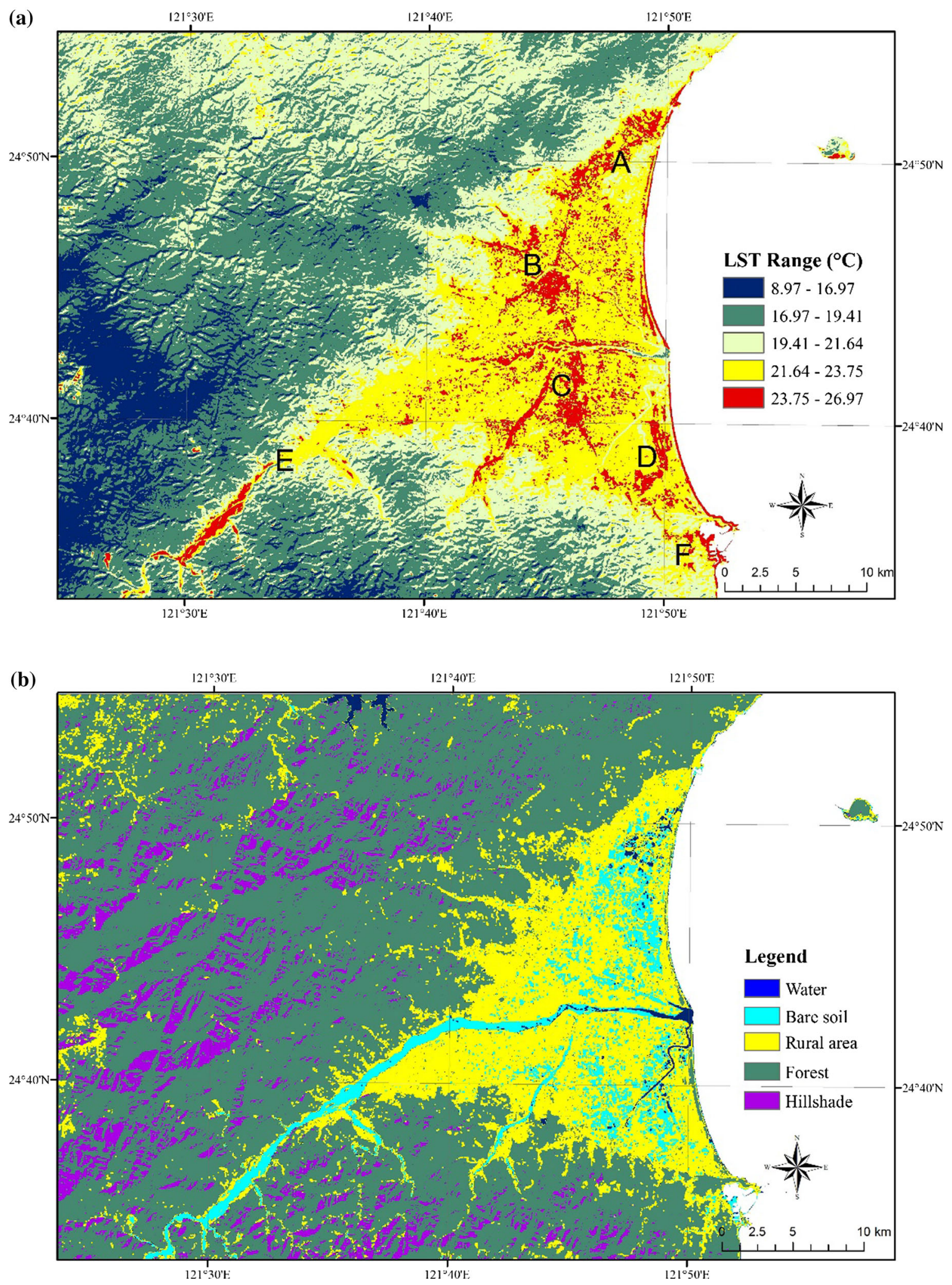


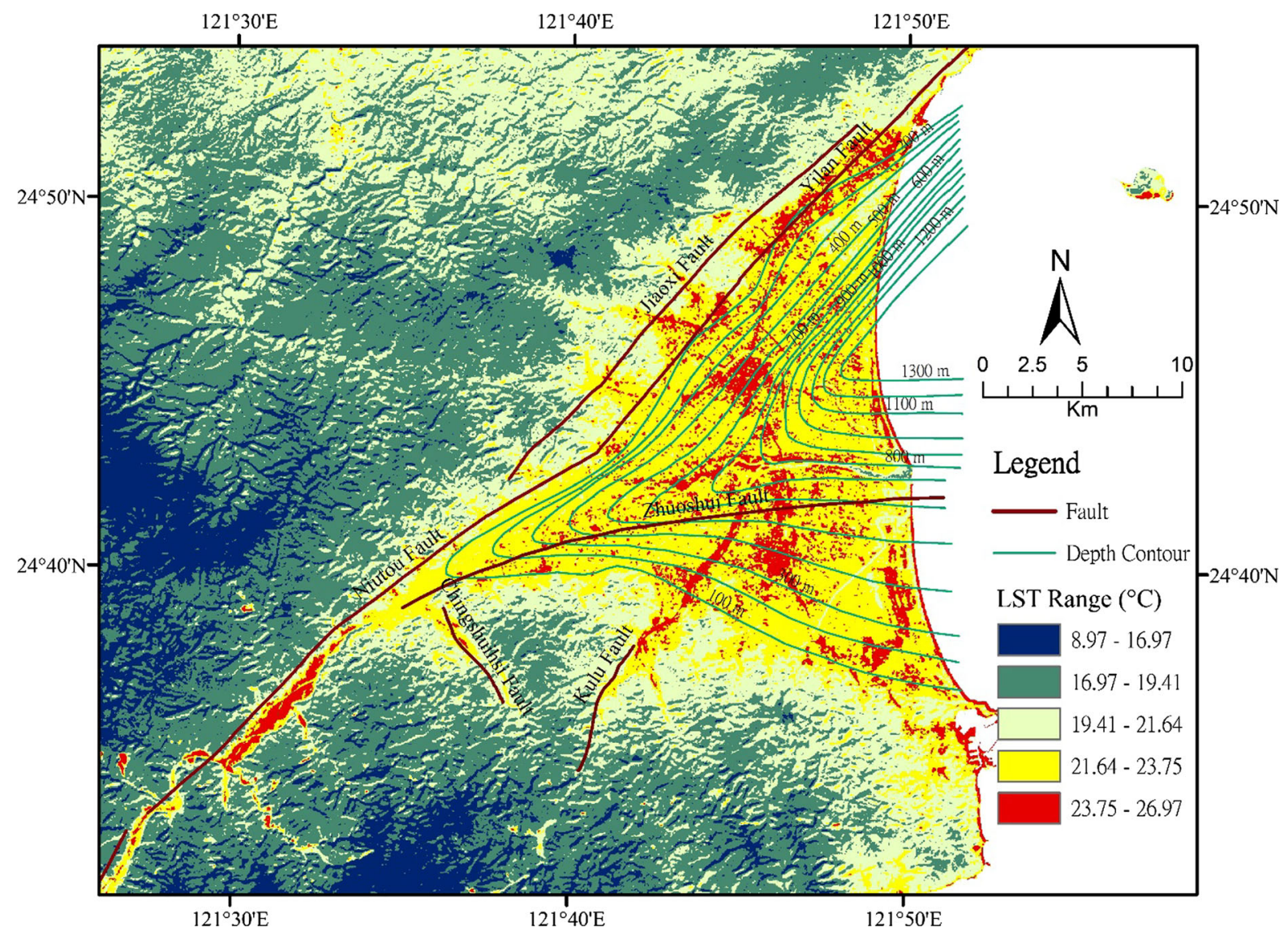

Figure 10

LST compared with fault structure (dark umber bold line) and basement depth contour (blue line) in Ilan plain

plain is mainly distributed in the southern portion. Tectonically, the plain is usually divided into two entities: the Ilan basin in the north and its collision zone in the south. The Ilan basin related to Okinawa Trough is an extension setting dominated by normal faults and the collision zone is in the compressive condition caused by the arc-continental collision (Huang et al. 2012). Figure 10 shows the faults and subsurface structure beneath the Ilan plain through seismic proofing (Liu 1995).

Comparing thermal anomaly areas in Fig. 9a with the fault structure and basement depth in Fig. 10, it shows that spatial correlations between thermal anomalies and faults for areas near mountains (i.e., area A, D, E and F in Fig. 9a) is more significant than areas near the plain center (i.e., area $\mathrm{B}$ and $\mathrm{C}$ in Fig. 9a). This pattern may be caused by the thickness of sediment deposits where shallow deposit area has the better heat transfer efficiency. The urban heat island (UHI) effect in the subsurface should also be accounted for thermal anomaly areas B (Ilan City) and $\mathrm{C}$ (Loudong Town), considering the fact that Ilan plain is basically a rural area in Taiwan and the pixel size of satellite imagery used is $30 \mathrm{~m}$ by $30 \mathrm{~m}$.

\subsection{Multi-temporal Brightness Temperature Imagery for the Verification of the LST Anomaly Results}

LST anomaly maybe affected by the precipitation history and soil moisture in different seasons of the year. Thus, a single Landsat ETM+ scene on December 3, 2001 is may not be sufficient for the proof of LST anomaly results shown in Fig. 9a. For 

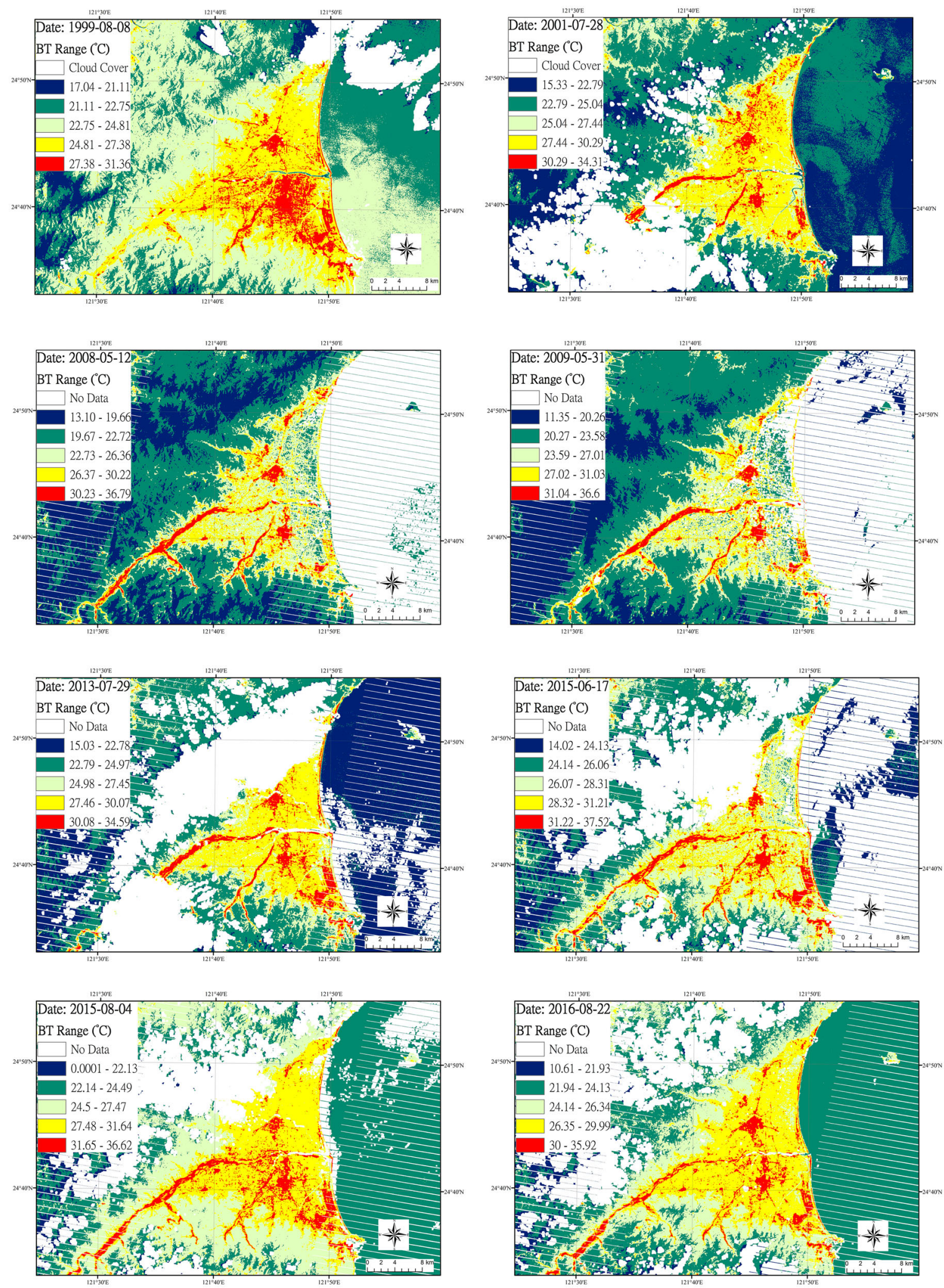
Figure 11

Pattern of Brightness Temperature distribution in Ilan plain from Landsat 7 ETM+ on 8 August 1999, 28 July 2001, 12 May 2008, 31 May 2009, 29 July 2013, 17 June 2015, 4 August 2015, and 22 August 2016, respectively. Blank areas (white color) indicate "No Data" caused by either cloud coverage or image gaps. Thermal anomalous areas are illustrated by red color in the imagery

Table 5

Statistic summary of Landsat ETM + multi-temporal brightness temperature imagery in the study area

\begin{tabular}{lllll}
\hline Imagery acquisition date & \multicolumn{2}{l}{$\mathrm{BT}\left({ }^{\circ} \mathrm{C}\right)$} & \multicolumn{2}{c}{$\begin{array}{l}\text { Cloud/image gaps } \\
\text { coverage (\%) }\end{array}$} \\
\cline { 2 - 4 } & Min & Max & Mean & \\
\hline 8-Aug-1999 & 14.3 & 35.4 & 23.4 & 6.4 \\
28-Jul-2001 & 15.4 & 38.6 & 24.2 & 22.2 \\
12-May-2008 & 13.2 & 40.8 & 21.3 & 26.7 \\
31-May-2009 & 11.5 & 42.1 & 21.8 & 28.7 \\
29-Jul-2013 & 14.3 & 37.2 & 24.3 & 36.6 \\
17-Jun-2015 & 13.8 & 40.9 & 26.1 & 46.1 \\
4-Aug-2015 & 10.5 & 40.0 & 25.3 & 32.1 \\
22-Aug-2016 & 10.5 & 37.3 & 24.4 & 29.2 \\
\hline
\end{tabular}

the verification of LST anomaly in Ilan plain. Additional 8 imageries of different year and season (Acquisition date: 1999-08-08, 2001-07-28, 2008-0512, 2009-05-31, 2013-07-29, 2015-06-17, 2015-0804, and 2016-08-22) which selected meticulously from the Landsat archive were processed to obtain the brightness temperature (BT) of the study area as shown in Fig. 11 and Table 5. The BT is the radiance measurement of the electromagnetic radiation traveling upward from the top of the atmosphere to the satellite, expressed in units of the temperature of an equivalent black body. The ratio between the BT and LST is known as surface emissivity. Since surface emissivity in the nature is smaller than one. Therefore, LST is always higher than BT.

All the selected images suffered from the cloud coverage or image gap caused by the satellite's mechanical malfunction. However, the study-interested triangle Ilan plain is mostly retained in the imagery. The imagery set from 1999 to 2016 shows clear consistency in the thermal anomaly area discussed above (A, B, C, D, E and F as shown in Fig. 9a.) which provides ample support for the LST anomaly results.

\subsection{Spatial Correlation Between LST Anomaly and Geothermal Occurrences, Faults and Resistivity Profiles}

The selected thermal anomaly areas can be validated by the field investigation as shown in Fig. 12. Results indicate that area A, E, and F are three sightseeing geothermal landscapes of tourist attractions. Hot springs and hydrothermal explosions are widely distributed in these geothermal areas. For example, the hot spring in area A, Jiaoxi hot spring is the most historic hot spring site, which is quite rare in Taiwan for its occurrence on a flatland. Meanwhile, Tangwei hot spring (Tangweigou Park) in area A has been famous since Qing dynasty (ruling from 1644 to 1912 AD in China) and placed on the list of "Eight scenes of Lanyang area". In the mountain area near E, Chinhsui geothermal park is also a well-known geothermal spot located in the Chinhsui river valley, southwest to Ilan plain. The temperature of the spring water is as high as $95{ }^{\circ} \mathrm{C}$, and its geothermal energy resources are located beneath the shallow riverbed. In area F, both hot and cold springs occur at Suao, which is one of the three rarest cold spring sites in the world. Area D features with the two drilling wells with the high geothermal gradient of $6.2{ }^{\circ} \mathrm{C} / 100 \mathrm{~m}$ depth (Lize well) and $7.6{ }^{\circ} \mathrm{C} / 100 \mathrm{~m}$ depth (Longde well), respectively. Finally, it should also be noted that in the area of Lanyang River, which is the main river of Ilan plain in between area B and C, thermal anomaly pattern obviously shows the continuous point-shaped distribution along the riverbank. Geothermal drillings such as Wujie well $\left(4.3{ }^{\circ} \mathrm{C} /\right.$ $100 \mathrm{~m})$, Dazhou well $\left(5.3^{\circ} \mathrm{C} / 100 \mathrm{~m}\right)$ and Gengshen well $\left(7.5^{\circ} \mathrm{C} / 100 \mathrm{~m}\right)$ are approximately distributed by way of the Zhuoshui fault in between area B and C. They might as well have certain correlations with the fault pattern in this area. Correspondingly, other faults (e.g., Niutou, Jiaoxi, Yilan, Chingshuihsi and Kulu faults) also display the similar pattern of correlation.

Magnetotelluric (MT) survey is applied for exploring structures of the geothermal reservoir. Thirty-three broadband magnetotelluric data by the ITRI were analyzed for the Chingshui geothermal area is shown in Fig. 13. Profile A (A-A', NE-SW) and profile $\mathrm{B}\left(\mathrm{B}-\mathrm{B}^{\prime}, \mathrm{NW}-\mathrm{SE}\right)$ are determined for the 


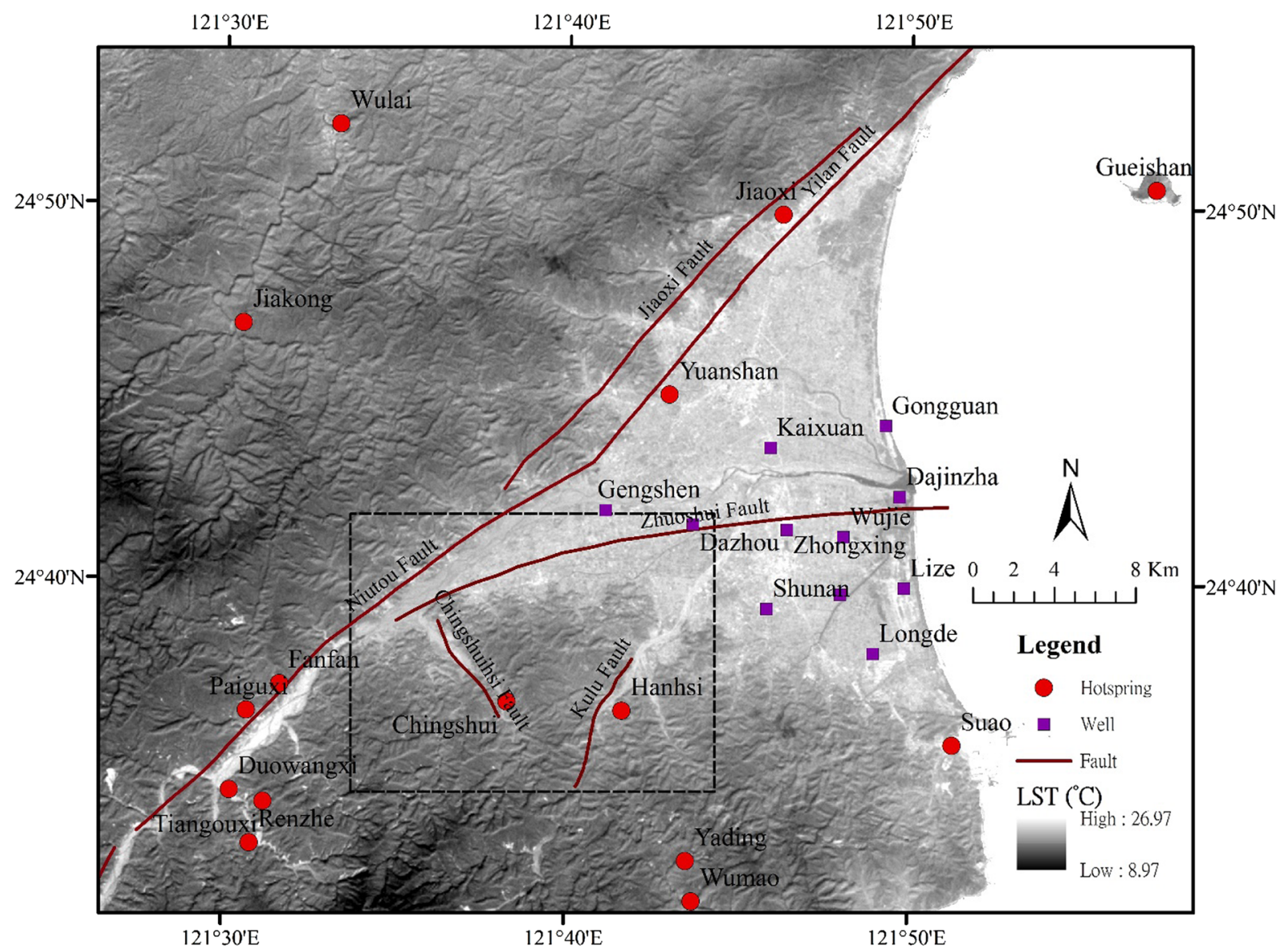

Figure 12

Geothermal drillings and hot springs in Ilan area. Purple squares in the plain indicate geothermal drillings and red circles annotate hot springs. The dashed box shows the Chingshui geothermal area in Fig. 13

resistivity analysis. After electric fields and magnetic fields were calculated as a function of frequency, resistivity sections were then obtained for these two profiles by 2D data inversion (Tong et al. 2008).

Figure 14c, d shows the 2-D resistivity sections of profiles $\mathrm{A}$ and $\mathrm{B}$, respectively. Figure $14 \mathrm{a}, \mathrm{b}$ are the corresponding LST profiles. Comparing resistivity sections with LST profiles (i.e., Fig. 14a, b vs. Fig. 14c, d), the horizontal axes are aligned to the same distance and locations. The vertical axes indicate variations on LST and resistivity. The significant low-resistivity zones observed in the resistivity sections (Fig. 14c, d) are echoed with the low-temperature zones of LST profiles (Fig. 14a, b). The subsurface resistivity is affected by the combined effects of temperature, pressure, mineral composition, geological structure, fluid, and partial melting. Generally, the decrease in pressure or the increase in the temperature, pore fluid, and the proportion of high conductive minerals (such as magnetite, sulfide minerals, etc.) in the rock will lead the decrease of resistivity. Previous MT surveys in the study area show that conductive structures with significant low-resistivity (less than $100 \Omega$-m) usually were identified as the fracture zone (Chang et al. 2014; Ho et al. 2014). The lowresistivity zones in the resistivity sections (Fig. 14c, d) contain rocks with higher porosity and permeability, and water saturation (amount of water), may subsequently lead to the lower temperature on LST.

Emphasis should be made that the analysis in this study concerns temperature anomalies rather than absolute temperatures. Temperature anomaly is defined as the departure from a reference value. 


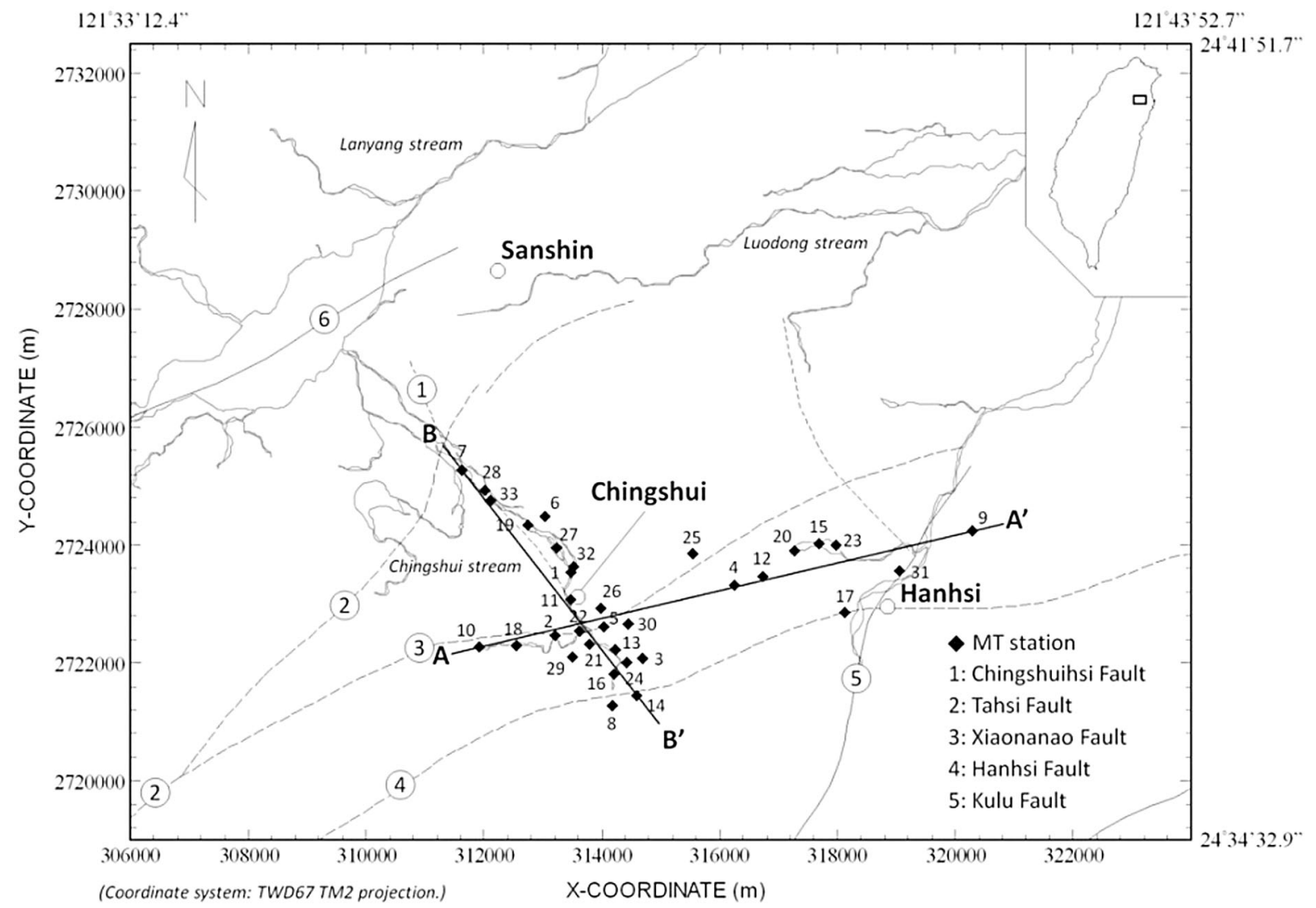

Figure 13

MT stations in the Chingshui geothermal area. Most stations are confined in the valley because of the hilly topography. Profile A (A-A', NE$\mathrm{SW})$ and profile B (B-B', NW-SE) are constructed for further analysis (Tong et al. 2008)

Absolute temperatures may vary notably in short distances due to various factors described in Sect. 2.3, while temperature anomalies are representative of a much larger scale. They present a frame of reference that provides much meaningful comparisons among locations, which is deemed to be more suitable for geothermal prospecting.

In summary, LST is accountable for the localized temperature anomaly which primarily came from solar radiation and the Earth's interior heat. Thus, comprehension of surface energy balance and underground heat transfer will facilitate the detection of geothermal regions. It is suggested that the volcanic intrusion inferred by magnetic anomaly could be the heat source of the high geothermal in the study area. A 3D geothermal conceptual model of Chingshui geothermal field was also proposed (Tong et al.
2008). However, the mechanism of geothermal anomaly for Ilan plain is needed for further verification.

\section{Conclusions and Future Directions}

This study aims to apply and integrate TIR remote sensing technology with existing geophysical methods for geothermal prospecting in Taiwan. Land surface temperature (LST) has been retrieved from the calibrated NASA Landsat 7 ETM+ data. Accuracy assessment of satellite-derived LST is conducted by comparing with the ground-truth air temperature data and the MODIS LST product. Landsat ETM+ derived LST anomaly results were verified by the multi-temporal brightness temperature images. Six 
(a)

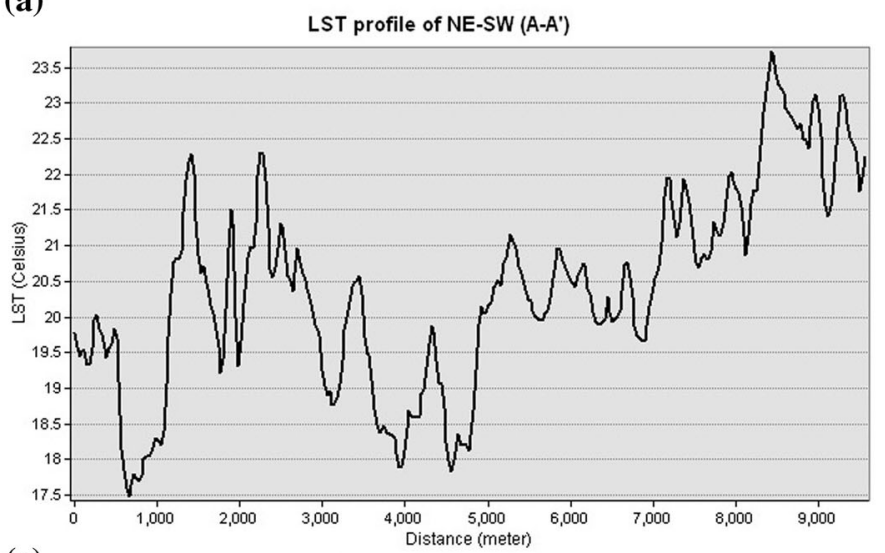

(c)

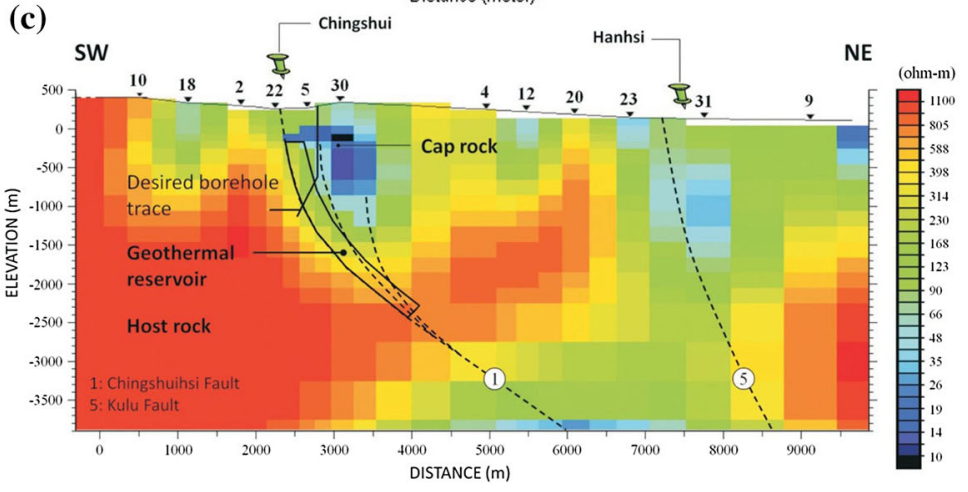

(b)

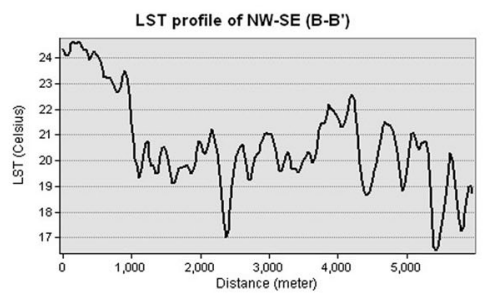

(d)

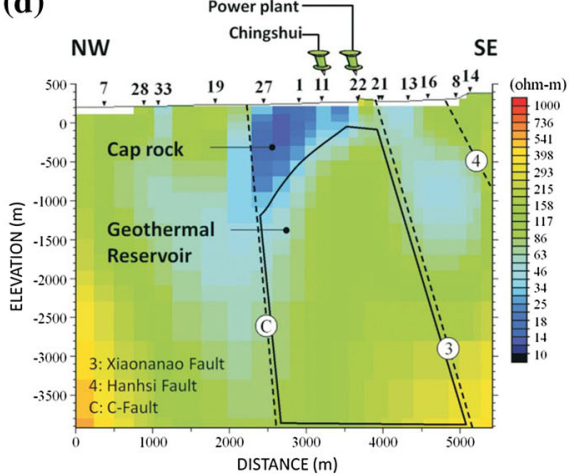

Figure 14

LST profiles compared with MT resistivity section of profile A and profile B from Tong et al. 2008. The low-resistivity zones identified in the resistivity sections (c, $\mathbf{d})$ are echoed in the LST profiles $(\mathbf{a}, \mathbf{b})$

thermal anomaly areas (A, B, C, D, E and F as shown in Fig. 9a) with overall $3-6{ }^{\circ} \mathrm{C}$ higher than the ambient background temperature are determined in the study area. Among them, selected geothermal anomaly areas (A, D, E and F) are validated in detail by the field investigation of hot springs and geothermal drillings. Results imply that occurrences of hot springs and geothermal drillings are in close agreement with anomaly areas. Thermal anomaly patterns also indicate that the distributions of geothermal areas appear correlating with the development of faulted structures in Ilan plain. The significant low-resistivity zones identified in the resistivity sections are echoed with the LST profiles when compared with the Chingshui area.

This work suggests that TIR remote sensing is a valuable tool for thermal anomaly detection and mapping with its high efficiency, cost-effective, and accuracy in temperature retrieval. TIR remote sensing provides a rapid way of mapping and quantifying surface features to facilitate the exploration and assessment of geothermal resources (Kuenzer and Dech 2013). Most significantly, compared with conventional in situ methods of point measurements, remote sensing methods are able to produce reliable results which are spatially representative at larger regional scales. However, it is limited to detecting the surficial and the shallow buried geothermal resources. Thus, TIR remote sensing cannot be expected to suffice as the sole tool for exploring and monitoring geothermal resources. Further geologic analysis and mechanisms of geothermal anomaly are needed to assist the identification of geothermal areas. The integration of geothermal mechanism with the structure geology analysis will greatly improve the applicability of geothermal detection using TIR 
remote sensing. Future research focus is to incorporate the heat conservation equation and the rich of previous geophysical research efforts to estimate spatially distributed surface fluxes for the establishment of a geothermal 3D model in Ilan plain.

\section{Acknowledgements}

The authors very much appreciate MOST's support of this work through Grant MOST 105-2116-M-008-023. Landsat 7 ETM+ scenes are courtesy of the US Geological Survey. The USGS home page is http:// www.usgs.gov. Meteorological temperature data and seismic catalog supplied by courtesy of the Central Weather Bureau (CWB) of Taiwan. The CWB home page is http://www.cwb.gov.tw/V7e/index_home. $\mathrm{htm}$. The authors are very grateful to the three anonymous reviewers for their valuable and insightful comments, which have been improved the manuscript substantially. The authors would also like to express appreciation to the editorial board and editorial staff. Sincerest thanks for all the expertise and hard work invested in this paper. As a final note, we would like to express our affection and friendship towards Prof. JihHao Hung. The preparation of this paper has been overshadowed by Prof. Jih-Hao Hung's decease in May, 2015. We had intended to work and publish jointly. We dedicate this work to his memory.

Open Access This article is distributed under the terms of the Creative Commons Attribution 4.0 International License (http:// creativecommons.org/licenses/by/4.0/), which permits unrestricted use, distribution, and reproduction in any medium, provided you give appropriate credit to the original author(s) and the source, provide a link to the Creative Commons license, and indicate if changes were made.

\section{REFERENCES}

Adler-Golden, S., Berk, A., Bernstein, L., Richtsmeier, S., Acharya, P., Matthew, M., Anderson, G., Allred, C., Jeong, L., Chetwynd, J. (1998). FLAASH, a MODTRAN4 atmospheric correction package for hyperspectral data retrievals and simulations. In Proceedings of 7th Annual JPL Airborne Earth Science Workshop (pp. 9-14).

Akhoondzadeh, M. (2013). A comparison of classical and intelligent methods to detect potential thermal anomalies before the 11 August 2012 Varzeghan, Iran, earthquake $(M=6.4)$. Natural Hazards and Earth System Science, 13, 1077-1083.
Artis, D. A., \& Carnahan, W. H. (1982). Survey of emissivity variability in thermography of urban areas. Remote Sensing of Environment, 12, 313-329.

Barsi, J., Barker, J.L., Schott, J.R. (2003). An atmospheric correction parameter calculator for a single thermal band earthsensing instrument, geoscience and remote sensing symposium, 2003. In: IEEE IGARSS'03 Proceedings. 2003 IEEE International (pp. 3014-3016).

Butler, J.J., Barsi, J.A., Schott, J.R., Palluconi, F.D., Hook, S.J. (2005). Validation of a web-based atmospheric correction tool for single thermal band instruments. In: Proceedings of SPIE, Bellingham, WA,.vol. 5882, p. 7.

Chang, T.-Y., \& Liou, Y. A. (2005). Using Landsat data-derived air temperature to quantify the magnitude of urban heat island effect. Journal of Photogrammetry and Remote Sensing, 10, 385-392.

Chang, T.-Y., Liou, Y.-A., Lin, C.-Y., Liu, S.-C., \& Wang, Y.-C. (2010). Evaluation of surface heat fluxes in Chiayi plain of Taiwan by remotely sensed data. International Journal of Remote Sensing, 31, 3885-3898.

Chang, P.-Y., Lo, W., Song, S.-R., Ho, K.-R., Wu, C.-S., Chen, C.S., et al. (2014). Evaluating the Chingshui geothermal reservoir in northeast Taiwan with a 3D integrated geophysical visualization model. Geothermics, 50, 91-100.

Chiang, S., Lin, J., Chang, C.R., Wu, T. (1979). A preliminary study of the Chingshui geothermal area, Ilan, Taiwan. In Proceeding of the 5th Geothermal Reservoir Engineering Workshop, Stanford University, Stanford, California (pp. 249-254).

Chiang, H.T., Shyu, C.T., Chang, H.I. (2007). A study of shallow geothermal resources in Ilan Plain, Northeastern Taiwan. In CIMME Annual Convention, October 26th, 2007, Kaohsiung, Taiwan.

Chien, T.-C., Liou, Y.-A., \& Chang, T.-Y. (2008). Using remote sensing to estimate evapotranspiration of paddy field. Journal of Photogrammetry and Remote Sensing, 13, 1-18.

Coll, C., Wan, Z., Galve, J.M. (2009). Temperature-based and radiance-based validations of the V5 MODIS land surface temperature product. Journal of Geophysical Research: Atmospheres, 114, D20102. doi:10.1029/2009JD012038

Davies, A. G., Calkins, J., Scharenbroich, L., Vaughan, R. G., Wright, R., Kyle, P., et al. (2008). Multi-instrument remote and in situ observations of the Erebus Volcano (Antarctica) lava lake in 2005: a comparison with the Pele lava lake on the jovian moon Io. Journal of Volcanology and Geothermal Research, 177, 705-724.

Gaudin, D., Beauducel, F., Allemand, P., Delacourt, C., \& Finizola, A. (2013). Heat flux measurement from thermal infrared imagery in low-flux fumarolic zones: example of the Ty fault (La Soufrière de Guadeloupe). Journal of Volcanology and Geothermal Research, 267, 47-56.

Gutiérrez, F. J., Lemus, M., Parada, M. A., Benavente, O. M., \& Aguilera, F. A. (2012). Contribution of ground surface altitude difference to thermal anomaly detection using satellite images: application to volcanic/geothermal complexes in the Andes of Central Chile. Journal of Volcanology and Geothermal Research, 237-238, 69-80.

Ho, G.-R., Chang, P.-Y., Lo, W., Liu, C.-M., Song, S.-R. (2014). New evidence of regional geological structures inferred from reprocessing and resistivity data interpretation in the ChingshuiSanshing-Hanchi area of Southwestern Ilan County, NE Taiwan. Terrestrial, Atmospheric \& Oceanic Sciences, 25(4), 191--504. 
Ho, H.-C., \& Chen, M.-M. (2000). Explanatory text of the geologic map of Taiwan. MOEA: Central Geological Survey.

Huang, H.H., Shyu, J.B.H., Wu, Y.M., Chang, C.H., Chen, Y.G. (2012). Seismotectonics of northeastern Taiwan: Kinematics of the transition from waning collision to subduction and postcollisional extension. Journal of Geophysical Research: Solid Earth, 117, B01313 doi:10.1029/2011JB008852.

Kang, C.-C., Chang, C.-P., Siame, L., \& Lee, J.-C. (2015). Present-day surface deformation and tectonic insights of the extensional Ilan Plain, NE Taiwan. Journal of Asian Earth Sciences, 105, 408-417.

Kruse, F. A. (2012). Mapping surface mineralogy using imaging spectrometry. Geomorphology, 137, 41-56.

Kuenzer, C., \& Dech, S. (2013). Thermal infrared remote sensing: sensors, methods, applications. Remote Sensing and Digital Image Processing, vol 17. New York: Springer.

Kuenzer, C., Zhang, J., Li, J., Voigt, S., Mehl, H., \& Wagner, W. (2007). Detecting unknown coal fires: synergy of automated coal fire risk area delineation and improved thermal anomaly extraction. International Journal of Remote Sensing, 28, $4561-4585$.

Lee, C. (1999). Neotectonics and active faults in Taiwan (pp. 61-74). Foster City: Workshop on Disaster Prevention/Management and Green Technology.

Li, F., Jackson, T. J., Kustas, W. P., Schmugge, T. J., French, A. N., Cosh, M. H., et al. (2004). Deriving land surface temperature from Landsat 5 and 7 during SMEX02/SMACEX. Remote Sensing of Environment, 92, 521-534.

Liu, C. (1995). The Ilan plain and the southwestward extending Okinawa Trough. Journal of the Geological Society of China, 38, 183-193.

Mellon, M. T., Jakosky, B. M., Kieffer, H. H., \& Christensen, P. R. (2000). High-resolution thermal inertia mapping from the Mars global surveyor thermal emission spectrometer. Icarus, 148, 437-455.

Mia, M. B., Bromley, C. J., \& Fujimitsu, Y. (2012). Monitoring heat flux using Landsat TM/ETM + thermal infrared data: A case study at Karapiti ('Craters of the Moon') thermal area, New Zealand. Journal of Volcanology and Geothermal Research, 235-236, 1-10.

Mia, M. B., Bromley, C. J., \& Fujimitsu, Y. (2013). Monitoring heat losses using Landsat ETM+ thermal infrared data: A case study in Unzen geothermal field, Kyushu, Japan. Pure and Applied Geophysics, 170, 2263-2271.

NASA, Landsat 7 science data users handbook-data products (1998). NASA's Goddard Space Flight Center. [Online]. http:// landsathand-book.gsfc.nasa.gov/pdfs/Landsat7Handbook.pdf. Accessed 27 Mar 2014

NASA, Landsat processing details (2015). NASA's Goddard Space Flight Center. [Online]. https://landsat.usgs.gov/Landsat_ Processing_Details.php. Accessed 15 June 2017.

NASA, frequently asked questions about the Landsat missions (2013). NASA's Goddard Space Flight Center. http://landsat. usgs.gov/band_designations_landsat_satellites.php. Accessed 27 Mar 2014.

Oguro, Y., Ito, S., \& Tsuchiya, K. (2011). Comparisons of brightness temperatures of Landsat-7/ETM+ and Terra/MODIS around Hotien Oasis in the Taklimakan Desert. Applied and Environmental Soil Science, 2011, 1-11.

Price, J. C. (1977). Thermal inertia mapping: a new view of the earth. Journal of Geophysical Research, 82, 2582-2590.

Qin, Q., Zhang, N., Nan, P., \& Chai, L. (2011). Geothermal area detection using Landsat ETM+ thermal infrared data and its mechanistic analysis: a case study in Tengchong, China. International Journal of Applied Earth Observation and Geoinformation, 13, 552-559.

Quattrochi, D. A., \& Luvall, J. C. (2004). Thermal remote sensing in land surface processing. CRC Press.

Reath, K. A., \& Ramsey, M. S. (2013). Exploration of geothermal systems using hyperspectral thermal infrared remote sensing. Journal of Volcanology and Geothermal Research, 265, 27-38.

Schmugge, T., Hook, S., \& Coll, C. (1998). Recovering surface temperature and emissivity from thermal infrared multispectral data. Remote Sensing of Environment, 65, 121-131.

Shaw, J. A., Powell, S. L., Jewett, J. T., Custer, S. G., Lawrence, R. L., \& Savage, S. L. (2010). Review of alternative methods for estimating terrestrial emittance and geothermal heat flux for yellowstone national park using landsat imagery. GIScience \& Remote Sensing, 47, 460-479.

Sobrino, J. A., Jiménez-Muñoz, J. C., Sòria, G., Romaguera, M., Guanter, L., Moreno, J., et al. (2008). Land surface emissivity retrieval from different VNIR and TIR sensors. IEEE Transactions on Geoscience and Remote Sensing, 46, 316-327.

Sobrino, J., Raissouni, N., \& Li, Z.-L. (2001). A comparative study of land surface emissivity retrieval from NOAA data. Remote Sensing of Environment, 75, 256-266.

Song, S.-R. (2016). The geothermal potential, current and opportunity in Taiwan. In EGU General Assembly Conference Abstracts (p. 3376).

Tong, L.-T., Ouyang, S., Guo, T.-R., Lee, C.-R., Hu, K.-H., Lee, C.-L., et al. (2008). Insight into the geothermal structure in Chingshui, Ilan, Taiwan. Terrestrial, Atmospheric and Oceanic Sciences, 19, 413.

Tsanyao, F. (2015). Introduction to the geothermal energy program in Taiwan. Proceedings World Geothermal Congress, 2015, 19-24.

Vaughan, R. G., Keszthelyi, L. P., Davies, A. G., Schneider, D. J., Jaworowski, C., \& Heasler, H. (2010). Exploring the limits of identifying sub-pixel thermal features using ASTER TIR data. Journal of Volcanology and Geothermal Research, 189, 225-237.

Vaughan, R. G., Keszthelyi, L. P., Lowenstern, J. B., Jaworowski, C., \& Heasler, H. (2012). Use of ASTER and MODIS thermal infrared data to quantify heat flow and hydrothermal change at Yellowstone National Park. Journal of Volcanology and Geothermal Research, 233, 72-89.

Warner, T., \& Chen, X. (2001). Normalization of Landsat thermal imagery for the effects of solar heating and topography. International Journal of Remote Sensing, 22, 773-788.

Wu, W., Zou, L., Shen, X., Lu, S., Su, N., Kong, F., et al. (2012). Thermal infrared remote-sensing detection of thermal information associated with faults: a case study in Western Sichuan Basin, China. Journal of Asian Earth Sciences, 43, 110-117. 